\title{
Condições térmicas ambientais e desempenho de aves criadas em aviários com e sem o uso de forro
}

\author{
[Environmental thermal conditions and performance of broilers raised in aviaries with and without \\ the use of polyethylene lining] \\ P.G. Abreu, V.M.N. Abreu, A. Coldebella, F.R.F. Jaenisch, D.P. Paiva \\ Embrapa Suínos e Aves \\ Caixa Postal 21 \\ 89700-000 - Concórdia, SC
}

\begin{abstract}
RESUMO
$\mathrm{O}$ experimento foi realizado em delineamento inteiramente ao acaso, em esquema fatorial $2 \times 2$, para avaliar o efeito de época de ano, o tipo de forro de polietileno sobre as condições térmicas, de umidade e o desempenho de aves de corte. Foram utilizados quatro aviários, cada um dividido internamente em quatro boxes para alojar 200 aves cada. As variáveis de desempenho avaliadas foram peso vivo, ganho de peso, consumo de ração, conversão alimentar e mortalidade das aves do nascimento ao $42^{\circ}$ dia de idade. O desempenho das aves foi melhor com aviários com forro. As condições térmicas foram melhoradas $\mathrm{cm}$ a utilização de forro nos aviários.
\end{abstract}

Palavras-chave: frangos de corte, ambiente, isolamento térmico, forro

\begin{abstract}
This experiment was carried out in a completely randomized experimental design, factorial arrangement $2 \times 2$, to evaluate the effect of period of year and type polyethylene liming on thermal and humidity of aviaries and performance of broiler. Four aviaries were divided in four boxes to house 200 chickens each. The recorded performance traits were body weight, weight gain feed intake, feed:weght gain ratio and mortality from hatch to 42 days of age. Better thermal conditions and higher chicken performance were observed in the polyethylene liming aviaries.
\end{abstract}

Keywords: polyethylene lining, poultry, thermal insulation, broilers, environment

\section{INTRODUÇÃO}

No Brasil, um país de clima tropical com temperaturas elevadas de verão e intensa radiação, o material utilizado na construção de telhados de aviários deve permitir bom isolamento térmico para que a temperatura interna seja menos influenciável à variação climática e proporcione maior conforto térmico para as aves. Para manter essa temperatura interna dentro da zona de conforto térmico das aves, várias alternativas têm sido sugeridas, tais como: orientação e dimensões dos aviários, lanternim, quebra-ventos, sombreiros, tipos de cobertura, forros, ventiladores, paisagismo circundante e uso de material isolante. Essas alternativas devem ser adotadas antes de serem utilizados os sistemas de condicionamento térmico artificial (Abreu et al., 1999).

A proteção contra a insolação direta de telhados pode ser feita com o uso de coberturas com alto poder reflectivo, de isolantes térmicos e de material de grande inércia térmica (Abreu e Abreu, 2005). Forro como barreira física à radiação recebida e emitida pela cobertura no interior do aviário pode ser utilizado, pelo fato de permitir a formação de camada de ar junto à

Recebido em 20 de dezembro de 2005

Aceito em 17 de maio de 2007

E-mail: pabreu@cnpsa.embrapa.br 
cobertura e contribuir na redução da transferência de calor para as aves. As condições de conforto térmico em aviários com uso de forro na altura do pé-direito da instalação foram melhoradas, segundo Santos et al. (2002).

Outras técnicas para melhorar o desempenho das coberturas, como o uso de isolantes sobre as telhas (poliuretano) e sob as telhas (poliuretano, poliestireno extrusado, eucatex, lã de vidro ou similares e alumínio), também são indicadas. Em razão do custo elevado, esses isolantes não têm sido utilizados em larga escala na avicultura. Atualmente, uma alternativa de forro utilizada nos aviários é a película de polietileno, por ser de baixo custo.

A utilização de forro sob o telhado permite aumentar a densidade de criação de frangos e melhorar o desempenho das aves (Oliveira et al., 2000). Este trabalho foi realizado com o objetivo de avaliar o desempenho produtivo de aves e as condições térmicas ambientais em aviários com e sem o uso de forro.

\section{MATERIAL E MÉTODOS}

O experimento foi realizado em duas épocas $25 / 10 / 2003$ a $09 / 12 / 2003$ e 15/01/2004 a $26 / 02 / 2004$, em quatro aviários de $12 \mathrm{~m} \times 10 \mathrm{~m}$ para frangos de corte, divididos internamente em quatro boxes, com 200 aves cada.

O telhado do aviário foi construído com telhas de cimento amianto e lanternim ao longo da cumeeira. Os tratamentos testados foram aviários com e sem o uso de forro de polietileno, instalado na altura de $3 \mathrm{~m}$. As aves, machos da linhagem Ross, e a ração foram pesadas semanalmente, e as variáveis de desempenho estudadas foram: peso vivo (PV), ganho de peso (GP), consumo de ração (CR), conversão alimentar (CA) e mortalidade até o $42^{\circ}$ dia de idade. $\mathrm{O}$ delineamento experimental foi $\mathrm{O}$ inteiramente ao acaso em esquema fatorial $2 \times 2$ (época, tratamento) com oito repetições. Utilizou-se o programa de análises estatísticas SAS (System..., 2001), e médias foram comparadas pelo teste Tukey a $5 \%$.

Para a análise do ambiente térmico, as coletas de dados foram realizadas duas vezes por semana, a partir do início da quarta semana de vida das aves, registrando-os de três em três horas. Assim, nas três semanas, duas vezes por semana, realizaram-se nove medidas de cada vez. Para tal, foram instalados em cada boxe e no ambiente externo: um termômetro de bulbo seco, um termômetro de bulbo úmido e um termômetro de globo negro. Os dados de velocidade do ar (anemômetro) também foram registrados. Com base nos dados coletados em cada horário, no ambiente térmico externo e interno, para cada boxe foi determinada a umidade relativa do ar (UR) e calculados o índice de temperatura de globo e umidade (ITGU) e a carga térmica radiante (CTR).

A análise dos dados foi realizada considerandose o procedimento MIXED do SAS (System.., 2001), utilizando a proposta por Xavier (2000). A matriz de covariâncias foi escolhida com base no critério de informação de Akaike (AIC). Para o detalhamento do efeito de horário, a análise foi refeita mediante ajuste inicial de curvas de crescimento de terceiro grau, retirando-se os efeitos fixos não significativos $(\mathrm{P}>0,05)$ até que todos os efeitos remanescentes fossem significativos $(\mathrm{P} \leq 0,05)$, seguindo os passos indicados por Xavier (2000).

\section{RESULTADOS E DISCUSSÕES}

Não se observou efeito da interação época versus tratamento para as variáveis de desempenho. Houve diferença significativa entre épocas para todas as variáveis estudadas, exceto para a conversão alimentar aos 21 e 42 dias de idade das aves (Tab. 1). Aos 21 dias de idade das aves, não houve diferença entre os tratamentos para as variáveis estudadas nas aves; aos 42 dias de idade, a diferença ocorreu para as variáveis peso vivo, ganho de peso e consumo de ração. O aviário com forro foi o que apresentou os melhores resultados. Estes resultados confirmaram os já encontrados por Oliveira et al. (2000), que verificaram efeito do isolamento térmico do telhado com o uso de forro sobre o desempenho de frangos de corte. A conversão alimentar não foi influenciada pelo uso do forro. No período estudado, as aves dos dois tratamentos superaram em torno de $107 \mathrm{~g}$ o peso vivo padrão da linhagem $(2.425 \mathrm{~g})$ para machos. 
Tabela 1. Média do peso vivo (g), ganho de peso (g), consumo de ração (g) e conversão alimentar aos 21 e 42 dias de idade das aves, de acordo com a época e o uso ou não de forro no aviário

\begin{tabular}{|c|c|c|c|}
\hline \multicolumn{4}{|c|}{ Peso vivo aos 21 dias (g) } \\
\hline Época & Sem forro & Com forro & Média \\
\hline 1 & 762 & 788 & $775 \mathrm{~b}$ \\
\hline 2 & 840 & 833 & $836 \mathrm{a}$ \\
\hline Média & 801 & 810 & \\
\hline \multicolumn{4}{|c|}{ Ganho de peso aos 21 dias (g) } \\
\hline Época & Sem forro & Com forro & Média \\
\hline 1 & 721 & 746 & $733 \mathrm{~b}$ \\
\hline 2 & 797 & 790 & $793 \mathrm{a}$ \\
\hline Média & 759 & 768 & \\
\hline \multicolumn{4}{|c|}{ Consumo de ração aos 21 dias (g) } \\
\hline Época & Sem forro & Com forro & Média \\
\hline 1 & 1,008 & 1,021 & $1,014 \mathrm{~b}$ \\
\hline 2 & 1,095 & 1,095 & $1,095 \mathrm{a}$ \\
\hline Média & 1,051 & 1,058 & \\
\hline \multicolumn{4}{|c|}{ Conversão alimentar aos 21 dias } \\
\hline Época & Sem forro & Com forro & Média \\
\hline 1 & 1,324 & 1,287 & 1,311 \\
\hline 2 & 1,306 & 1,314 & 1,310 \\
\hline Média & 1,315 & 1,306 & \\
\hline \multicolumn{4}{|c|}{ Peso vivo aos 42 dias (g) } \\
\hline Época & Sem forro & Com forro & Média \\
\hline 1 & 2,377 & 2,455 & $2.416 \mathrm{~b}$ \\
\hline 2 & 2,640 & 2,658 & $2.649 \mathrm{a}$ \\
\hline Média & $2,508 \mathrm{~B}$ & $2,556 \mathrm{~A}$ & \\
\hline \multicolumn{4}{|c|}{ Ganho de peso aos 42 dias (g) } \\
\hline Época & Sem forro & Com forro & Média \\
\hline 1 & 2,336 & 2,413 & $2,375 \mathrm{~b}$ \\
\hline 2 & 2,596 & 2,615 & $2,606 \mathrm{a}$ \\
\hline Média & $2,466 \mathrm{~B}$ & $2,514 \mathrm{~A}$ & \\
\hline \multicolumn{4}{|c|}{ Consumo de ração aos 42 dias (g) } \\
\hline Época & Sem Forro & Com Forro & Média \\
\hline 1 & 4,034 & 4,155 & $4,095 \mathrm{~b}$ \\
\hline 2 & 4,502 & 4,602 & $4,552 \mathrm{a}$ \\
\hline Média & $4,268 \mathrm{~B}$ & $4,379 \mathrm{~A}$ & \\
\hline \multicolumn{4}{|c|}{ Conversão alimentar aos 42 dias } \\
\hline Época & Sem forro & Com forro & Média \\
\hline 1 & 1,699 & 1,695 & 1,697 \\
\hline 2 & 1,706 & 1,731 & 1,719 \\
\hline Média & 1,702 & 1,713 & \\
\hline
\end{tabular}

Médias seguidas por letras distintas minúsculas na coluna ou maiúsculas na linha para cada característica estudada diferem entre si pelo teste Tukey $(\mathrm{P}<0,05)$.

$\mathrm{Na}$ Tab. 2 apresentam-se os níveis de significância das variáveis do estudo térmico do ambiente, segundo os tratamentos, as épocas e as horas de tomada dos dados.

Houve diferença significativa entre os tratamentos e as épocas para todas as variáveis estudadas. Somente a interação tratamento $\mathrm{x}$ época para todas as variáveis estudadas e tratamento $\mathrm{x}$ época $\mathrm{x}$ hora para a variável UR não foram significativas $(P>0,05)$. As equações ajustadas e os pontos de mínimo e máximo para temperatura do ar, ITGU, CTR e UR, em função do tratamento e da época, são apresentadas na Tab. 3 . 
Tabela 2. Níveis descritivos de probabilidade $(\operatorname{Pr}>\mathrm{F})$ para temperatura do ar (Temp), índice de temperatura de globo e umidade (ITGU), carga térmica radiante (CTR) e umidade relativa do ar (UR), em função dos efeito

\begin{tabular}{lccccc}
\hline CV & GL & Temp $^{1}$ & ITGU $^{1}$ & CTR $^{1}$ & UR $^{1}$ \\
\hline Trat & 1 & 0,0006 & 0,0047 & 0,0022 & 0,0444 \\
Época & 1 & $<, 0001$ & $<, 0001$ & 0,0001 & 0,0011 \\
Trat x Época & 1 & 0,8683 & 0,4291 & 0,9665 & 0,8165 \\
Hora & 8 & $<, 0001$ & $<, 0001$ & $<, 0001$ & $<, 0001$ \\
Trat x Hora & 8 & $<, 0001$ & 0,0009 & 0,0004 & 0,0054 \\
Época x Hora & 8 & $<, 0001$ & $<, 0001$ & $<, 0001$ & $<, 0001$ \\
Trat x Época x Hora & 8 & $<, 0001$ & $<, 0001$ & $<, 0001$ & 0,1436 \\
\hline
\end{tabular}

${ }^{1}$ Usou-se a estrutura fator analítico para matriz de variâncias e covariâncias.

Tabela 3. Equações ajustadas e pontos de mínimo e máximo para temperatura do ar, índice de temperatura de globo e umidade, carga térmica radiante e umidade relativa do ar, em função do tratamento e da época

\begin{tabular}{|c|c|c|c|c|c|c|c|}
\hline \multirow{2}{*}{ Tratamento } & \multirow{2}{*}{ Época } & \multirow{2}{*}{ Equação } & \multicolumn{2}{|c|}{ Mínimo } & \multicolumn{2}{|c|}{ Máximo } & \multirow{2}{*}{ Média } \\
\hline & & & Hora & Valor & Hora & Valor & \\
\hline \multicolumn{8}{|c|}{ Temperatura do $\operatorname{ar}\left({ }^{\circ} \mathrm{C}\right)$} \\
\hline Sem forro & 1 & $\hat{y}=18,6279-0,83 h+0,1532 h^{2}-0,0049 h^{3}$ & $03 \mathrm{~h} 12 \mathrm{~min}$ & 17,4 & $17 \mathrm{~h} 36 \mathrm{~min}$ & 24,8 & 20,68 \\
\hline Sem forro & 2 & $\hat{y}=16,4858-1,4625 h+0,249 h^{2}-0,0076 h^{3}$ & $03 \mathrm{~h} 30 \mathrm{~min}$ & 14,1 & $18 \mathrm{~h} 18 \mathrm{~min}$ & 26,5 & 19,78 \\
\hline Com forro & 1 & $\hat{y}=17,5263-0,593 h+0,136 h^{2}-0,0045 h^{3}$ & $02 \mathrm{~h} 30 \mathrm{~min}$ & 16,8 & $17 \mathrm{~h} 42 \mathrm{~min}$ & 24,7 & 20,42 \\
\hline Com forro & 2 & $\hat{y}=15,7167-1,32 h+0,2385 h^{2}-0,00739 h^{3}$ & $03 \mathrm{~h} 18 \mathrm{~min}$ & 13,7 & $18 \mathrm{~h} 18 \mathrm{~min}$ & 26,1 & 19,41 \\
\hline Externo & 1 & $\hat{y}=19,1966-0,3324 h+0,1316 h^{2}-0,0051 h^{3}$ & $1 \mathrm{~h} 24 \mathrm{~min}$ & 19,0 & $15 \mathrm{~h} 48 \mathrm{~min}$ & 26,7 & \\
\hline Externo & 2 & $\hat{y}=15,8266-0,3404 h+0,1902 h^{2}-0,00736 h^{3}$ & $0 \mathrm{~h} 54 \mathrm{~min}$ & 15,7 & $16 \mathrm{~h} 18 \mathrm{~min}$ & 28,9 & \\
\hline \multicolumn{8}{|c|}{ Índice de temperatura de globo e umidade } \\
\hline Sem forro & 1 & $\hat{y}=67,4187-0,8197 h+0,1542 h^{2}-0,00476 h^{3}$ & $3 \mathrm{~h} 06 \mathrm{~min}$ & 66,2 & $18 \mathrm{~h} 30 \mathrm{~min}$ & 74,9 & 69,77 \\
\hline Sem forro & 2 & $\hat{\mathrm{y}}=64,0963-1,7145 \mathrm{~h}+0,285 \mathrm{~h}^{2}-0,00827 \mathrm{~h}^{3}$ & $3 \mathrm{~h} 36 \mathrm{~min}$ & 61,2 & $19 \mathrm{~h} 24 \mathrm{~min}$ & 77,7 & 68,47 \\
\hline Com forro & 1 & $\hat{y}=67,0573-0,7855 h+0,1542 h^{2}-0,00476 h^{3}$ & $3 \mathrm{~h} 12 \mathrm{~min}$ & 65,9 & $18 \mathrm{~h} 54 \mathrm{~min}$ & 74,4 & 69,31 \\
\hline Com forro & 2 & $\hat{y}=63,194-1,5184 h+0,2667 h^{2}-0,00789 h^{3}$ & $3 \mathrm{~h} 18 \mathrm{~min}$ & 60,8 & $19 \mathrm{~h} 12 \mathrm{~min}$ & 76,5 & 67,68 \\
\hline Externo & 1 & $\hat{y}=65,8094+0,5798 \mathrm{~h}+0,1715 \mathrm{~h}^{2}-0,00844 \mathrm{~h}^{3}$ & $24 \mathrm{~h} 00 \mathrm{~min}$ & 61,8 & $15 \mathrm{~h} 06 \mathrm{~min}$ & 84,6 & \\
\hline Externo & 2 & $\hat{y}=59,6314+1,5237 \mathrm{~h}+0,1516 \mathrm{~h}^{2}-0,0089 \mathrm{~h}^{3}$ & $24 \mathrm{~h} 00 \mathrm{~min}$ & 60,5 & $15 \mathrm{~h} 06 \mathrm{~min}$ & 86,6 & \\
\hline \multicolumn{8}{|c|}{ Carga térmica radiante } \\
\hline Sem forro & 1 & $\hat{y}=416,31-5,5913 h+1,2407 h^{2}-0,04264 h^{3}$ & $2 \mathrm{~h} 36 \mathrm{~min}$ & 409,4 & $16 \mathrm{~h} 48 \mathrm{~min}$ & 470,4 & 430,02 \\
\hline Sem forro & 2 & $\hat{y}=406,02-8,4954 h+0,285 h^{2}-0,05828 h^{3}$ & $2 \mathrm{~h} 54 \mathrm{~min}$ & 394,5 & $17 \mathrm{~h} 00 \mathrm{~min}$ & 476,0 & 426,33 \\
\hline Com forro & 1 & $\hat{y}=412,52-4,7506 h+1,1686 h^{2}-0,04091 h^{3}$ & $2 \mathrm{~h} 18 \mathrm{~min}$ & 407,3 & $16 \mathrm{~h} 42 \mathrm{~min}$ & 468,6 & 429,11 \\
\hline Com forro & 2 & $\hat{\mathrm{y}}=401,38-7,7957 \mathrm{~h}+1,6604 \mathrm{~h}^{2}-0,05648 \mathrm{~h}^{3}$ & $2 \mathrm{~h} 42 \mathrm{~min}$ & 391,3 & $16 \mathrm{~h} 54 \mathrm{~min}$ & 471,2 & 423,31 \\
\hline Externo & 1 & $\hat{y}=370,3+26,7703 h+0,5202 h^{2}-0,06981 h^{3}$ & $24 \mathrm{~h} 00 \mathrm{~min}$ & 347,4 & $14 \mathrm{~h} 06 \mathrm{~min}$ & 655,5 & \\
\hline Externo & 2 & $\hat{\mathrm{y}}=311,01+48,9125 \mathrm{~h}-0,1425 \mathrm{~h}^{2}-0,07947 \mathrm{~h}^{3}$ & $24 \mathrm{~h} 00 \mathrm{~min}$ & 304,2 & $13 \mathrm{~h} 42 \mathrm{~min}$ & 750,0 & \\
\hline \multicolumn{8}{|c|}{ Umidade relativa } \\
\hline Sem forro & 1 & $\hat{y}=94,2471+0,426 \mathrm{~h}-0,08264 \mathrm{~h}^{2}+0,002912 \mathrm{~h}^{3}$ & $15 \mathrm{~h} 48 \mathrm{~min}$ & 91,8 & $3 \mathrm{~h} 06 \mathrm{~min}$ & 94,9 & 88,02 \\
\hline Sem forro & 2 & $\hat{y}=92,0092+1,1539 h-0,1826 h^{2}+0,005866 h^{3}$ & $16 \mathrm{~h} 54 \mathrm{~min}$ & 87,7 & $3 \mathrm{~h} 54 \mathrm{~min}$ & 94,1 & 84,85 \\
\hline Com forro & 1 & $\hat{y}=92,6846+0,3627 \mathrm{~h}-0,09332 \mathrm{~h}^{2}+0,003387 \mathrm{~h}^{3}$ & $16 \mathrm{~h} 12 \mathrm{~min}$ & 88,5 & $2 \mathrm{~h} 12 \mathrm{~min}$ & 93,1 & 86,28 \\
\hline Com forro & 2 & $\hat{\mathrm{y}}=91,8311+0,2218 \mathrm{~h}-0,07881 \mathrm{~h}^{2}+0,003069 \mathrm{~h}^{3}$ & $15 \mathrm{~h} 36 \mathrm{~min}$ & 87,8 & $1 \mathrm{~h} 30 \mathrm{~min}$ & 92,0 & 82,68 \\
\hline Externo & 1 & $\hat{y}=94,5413+1,3149 h-0,3121 h^{2}+0,0109 h^{3}$ & $16 \mathrm{~h} 42 \mathrm{~min}$ & 80,2 & $2 \mathrm{~h} 24 \mathrm{~min}$ & 96,1 & \\
\hline Externo & 2 & $\hat{\mathrm{y}}=93,3545+0,1686 \mathrm{~h}-0,432 \mathrm{~h}^{2}+0,01824 \mathrm{~h}^{3}$ & $15 \mathrm{~h} 36 \mathrm{~min}$ & 60,1 & $0 \mathrm{~h} 12 \mathrm{~min}$ & 93,4 & \\
\hline
\end{tabular}

As temperaturas do ar nos aviários sem forro foram mais elevadas que as dos aviários com forro, em ambas as épocas. De acordo com Abreu e Abreu (2000), a temperatura confortável para aves na quarta semana é de $23^{\circ} \mathrm{C}-26^{\circ} \mathrm{C}$, na quinta semana, de $20^{\circ} \mathrm{C}-23^{\circ} \mathrm{C}$, e na sexta e sétima semanas, de $20^{\circ} \mathrm{C}$. Assim, pela temperatura média, os tratamentos apresentaram condições de conforto térmico a partir da quinta semana de vida das aves. Como a temperatura máxima ocorre no período diurno, que é o mais estressante para as aves na fase de terminação, 
mesmo no aviário com forro, as condições ambientais não foram satisfatórias a partir da quinta semana de vida. No período noturno, as condições de temperatura ambiente estavam sempre abaixo da zona de conforto térmico para as aves.

Para o ITGU, que incorpora os efeitos combinados da temperatura de bulbo seco, umidade do ar, energia radiante e velocidade do ar, os valores médios do aviário com forro foram menores e melhores que os do aviário sem forro nas duas épocas. O mesmo ocorreu com a CTR e a UR. Os valores da CTR influenciaram os valores de temperatura do ar e do ITGU. Essa influência foi favorável nos aviários com forro. Os valores da UR mostraram-se acima das condições ideais de $60 \%-70 \%$ para criação de aves, segundo Abreu e Abreu (2000).
Na Fig. 1, observa-se que as temperaturas do ar foram mais elevadas na época 1 que na época 2 , no entanto, dentro dos aviários, na época 1 , as temperaturas mantiveram-se mais constantes nos aviários com ou sem forro, e nos sem forro foram mais elevadas. Isso pode ser mais facilmente visualizado quando se compararam os valores dos pontos máximo e mínimo de temperatura apresentados na Tab. 3. Moraes (1998) demonstrou que a utilização de forro em aviários com coberturas de telhas de barro, cimentoamianto e alumínio proporcionou 5,6\% de melhora no ambiente térmico, efeito mais acentuado na cobertura com telhas de cimentoamianto. Os aviários apresentaram o mesmo comportamento cíclico das curvas de temperatura do ambiente externo.

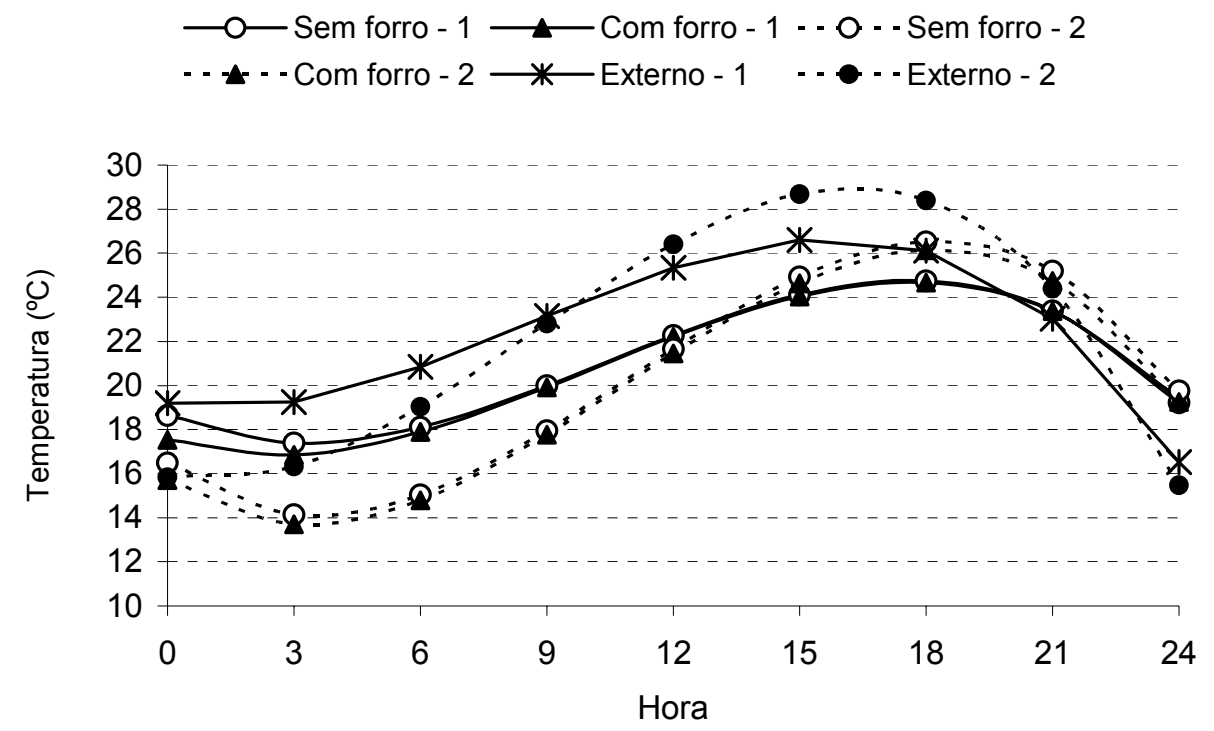

Figura 1. Curvas ajustadas da temperatura do ar, em função das horas, em aviários com e sem forro, nas épocas 1 e 2, dentro e fora do aviário.

O mesmo comportamento foi observado para ITGU (Fig. 2), isto é, as curvas na época 1 apresentaram-se mais homogêneas que as da época 2. Além disso, os valores de ITGU foram mais elevados nos aviários sem forro. Campos (1986), em pesquisa realizada no verão, em quatro galpões para frangos de corte, que se diferenciavam apenas quanto ao material de cobertura - telhas cerâmicas tipo francesa e telhas de cimento amianto, com e sem forro de esteira de taquara -, verificou que o uso de forro contribuiu significativamente para a melhoria do conforto térmico, avaliado pelo índice de temperatura de globo negro e umidade e carga térmica de radiação. Os melhores valores foram obtidos no interior do galpão coberto por telha de cerâmica com forro, e os piores no galpão com telhas de amianto sem forro. Santos et al (2002) encontraram valores menores de ITGU em aviários com forro, conferindo a esses menor inércia térmica.

A amplitude do ITGU no ambiente externo foi maior que a do ambiente interno. 

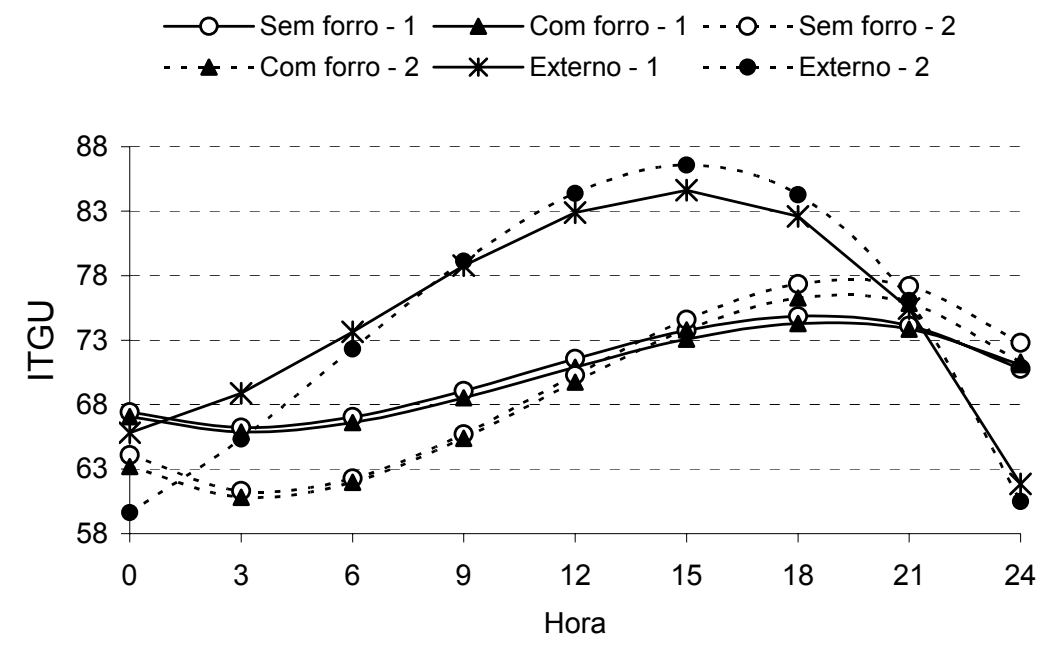

Figura 2. Curvas ajustadas para o índice de temperatura de globo e umidade em função das horas, em aviários com e sem forro, nas épocas 1 e 2, obtidas dentro e fora do aviário.

Para a CTR, nos aviários sem forro, ocorreram os valores mais altos, e, na época 1 , a radiação foi maior que na época 2 . As curvas apresentaram-se mais homogêneas tanto para a época 1 como para a 2 (Fig. 3). A amplitude da CTR no ambiente interno dos aviários com e sem forro foi menor que a do ambiente externo. De acordo com Nääs et al. (1995) e Santos et al. (2002), o uso de forro sob o telhado melhora o conforto térmico das aves pela redução da transmissão térmica e pelo aumento da sua inércia, conferindo ao ambiente menor CTR. As aves criadas dentro de aviários com e sem o uso de forro ficam menos expostas à carga térmica radiante que as aves criadas ao ar livre.

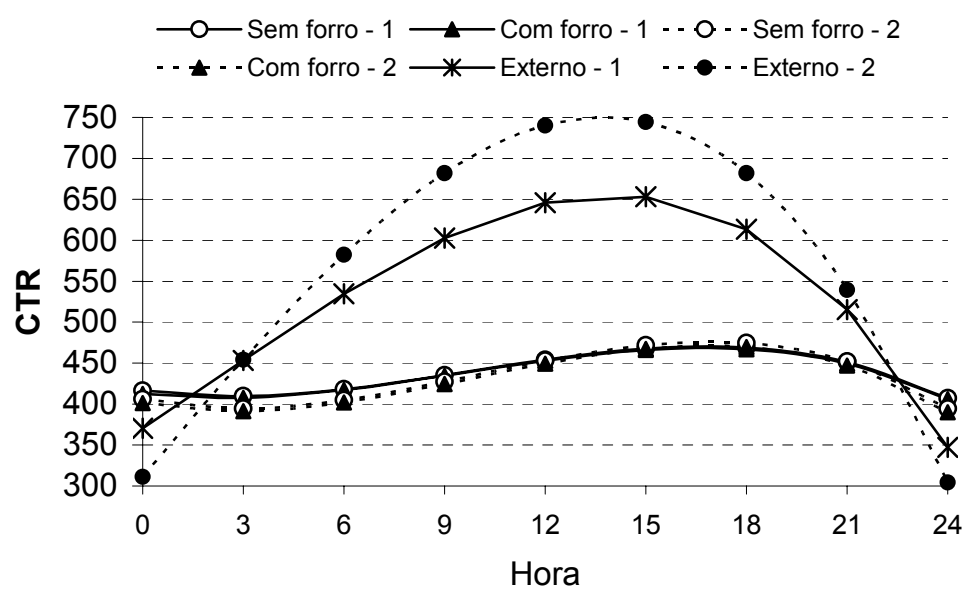

Figura 3. Curvas ajustadas para carga termıca radıante, em tunçāo das horas, em aviários com e sem forro, nas épocas 1 e 2, obtidas dentro e fora do aviário.

A UR (Fig. 4) também foi menor nos aviários com forro. Na época 1 ocorreu o mais alto valor de UR. Nas horas mais quentes do dia, em que se observa maior estresse calórico nas aves, a umidade relativa do ar foi mais alta em ambos os tratamentos, acima das condições ideais, e mais elevada que a do ambiente externo. É nesse período que os sistemas de resfriamento de evaporação do ar são acionados, o que forma as coberturas com forro mais propícias que as sem forro, por apresentarem menor UR. 


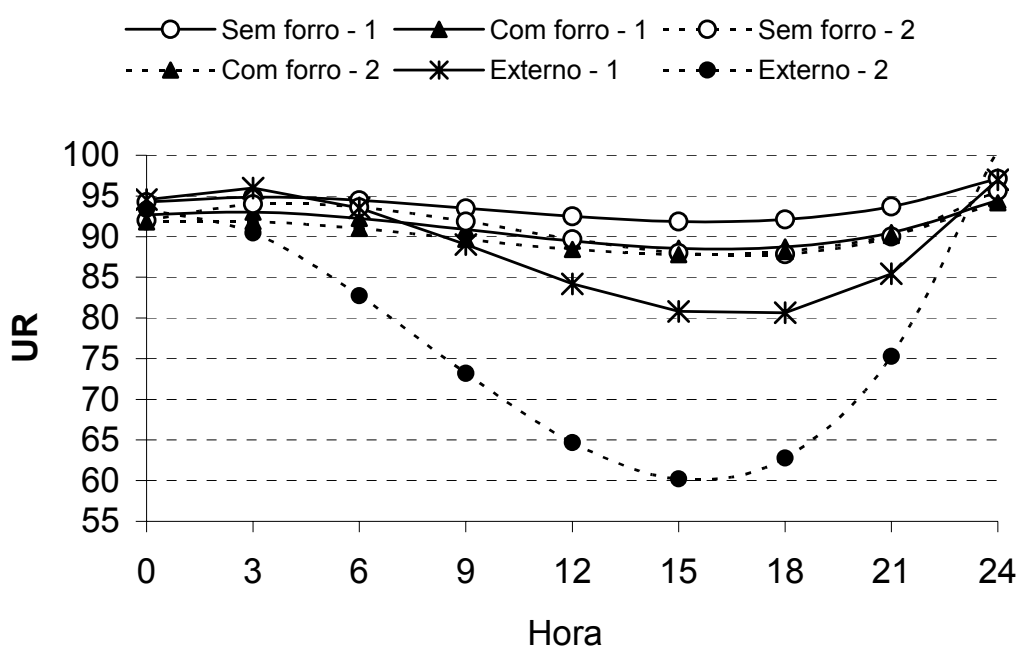

Figura 4. Curvas ajustadas para umidade relativa do ar, em função das horas, em aviários com e sem forro, nas épocas 1 e 2 , dentro e fora do aviário.

\section{CONCLUSÃO}

O uso do forro na cobertura dos aviários justifica-se pelo fato de resultar em melhores condições de conforto térmico para as aves.

\section{REFERÊNCIAS BIBLIOGRÁFICAS}

ABREU, P.G.; ABREU, V.M.N. Avaliação da temperatura da superfície de coberturas de abrigos abertos para aves coloniais. In: CONGRESSO BRASILEIRO DE AGROECOLOGIA, 3.; SEMINÁRIO ESTADUAL DE AGROECOLOGIA, 3., 2005, Florianópolis. Anais... Florianópolis, 2005. CD Rom.

ABREU, P.G.; ABREU, V.M.N. Ventilação na avicultura de corte. Concórdia: Embrapa Suínos e Aves, 2000. 50p. (Embrapa Suínos e Aves. Documentos, 63).

ABREU, P.G.; ABREU, V.M.N.; MAZZUCO, H. Uso do resfriamento evaporativo (adiabático) na criação de frangos de corte. Concórdia: EMBRAPA-CNPSA, 1999. 50p. (Documentos, 59).

CAMPOS, A.T. Determinação dos indices de conforto térmico e da carga térmica de radiação em quatro tipos de galpões, em condições de verão para Viçosa-MG. 1986. 66f. Tese (Mestrado) Universidade Federal de Viçosa, Viçosa, MG.
MORAES, S. R. P. Conforto térmico e módulos reduzidos de galpões avícolas para diferentes coberturas durante o verão. 1998. 73f. Tese (Mestrado) - Universidade Federal de Viçosa, Viçosa, MG.

NÄÄS, I.A.; MOURA, D.J.; LANGANÁ, C.A. A Amplitude térmica e seu reflexo na produtividade de frangos de corte. In: CONFERENNCIA APINCO DE CIÊNCIA E TECNOLOGIA AVÍCOLAS, 1995, Curitiba. Anais... Curitiba, 1995, p.203-204.

OLIVEIRA, J.E.; SAKOMURA, N.K.; FIGUEIREDO, N. et al. Efeito do isolamento térmico do telhado sobre o desempenho de frangos de corte alojados em diferentes densidades. Rev. Bras. Zootec., v.29, p.1427-1434, 2000.

SANTOS, R.C.; TINÔCO, I.F.F.; PAULO, M.O. et al. Análise de coberturas com telhas de barro e alumínio, utilizadas em instalações animais para duas distintas alturas de pé-direito. Rev. Bras. Eng. Agric. Amb., v.6, p.142-146, 2002.

SYSTEM for Microsoft Windows, Release 8.2. Cary, NC: SAS Institute, 1999-2001.

XAVIER, L.H. Modelos univariado e multivariado para análise de medidas repetidas e verificação da acurácia do modelo univariado por meio de simulação. 2000. Dissertação (Mestrado) - Escola Superior de Agricultura Luiz de Queiroz, Universidade de São Paulo, Piracicaba, SP. 